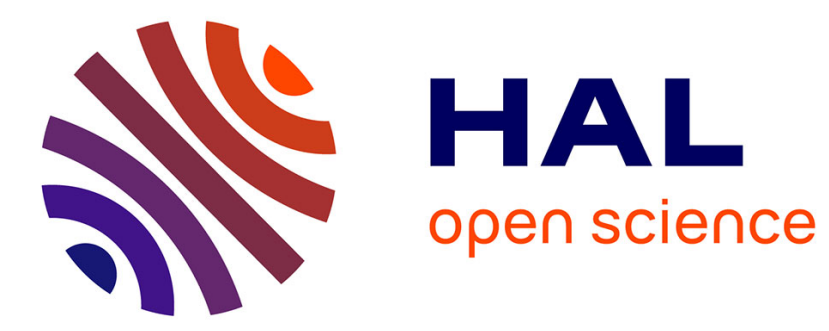

\title{
The aryl hydrocarbon receptor system
}

Robert Barouki, Martine Aggerbeck, Lawrence Aggerbeck, Xavier Coumoul

\section{To cite this version:}

Robert Barouki, Martine Aggerbeck, Lawrence Aggerbeck, Xavier Coumoul. The aryl hydrocarbon receptor system. Drug Metabolism and Drug Interactions, 2012, 27 (1), 10.1515/dmdi-2011-0035 . hal-02190803

\section{HAL Id: hal-02190803 https://hal.science/hal-02190803}

Submitted on 22 Jul 2019

HAL is a multi-disciplinary open access archive for the deposit and dissemination of scientific research documents, whether they are published or not. The documents may come from teaching and research institutions in France or abroad, or from public or private research centers.
L'archive ouverte pluridisciplinaire HAL, est destinée au dépôt et à la diffusion de documents scientifiques de niveau recherche, publiés ou non, émanant des établissements d'enseignement et de recherche français ou étrangers, des laboratoires publics ou privés. 


\section{Review}

\section{The aryl hydrocarbon receptor system}

\author{
Robert Barouki $^{1-3, *}$, Martine Aggerbeck ${ }^{1,2}$, \\ Lawrence Aggerbeck ${ }^{1,2}$ and Xavier Coumoul ${ }^{1,2}$ \\ ${ }^{1}$ INSERM UMR, Université Paris Descartes, Paris, France \\ ${ }^{2}$ Université Paris Descartes, Paris Sorbonne Cité, Centre \\ universitaire des Saints-Pères, Paris, France \\ ${ }^{3}$ APHP, Hôpital Necker Enfants Malades, Paris, France
}

\begin{abstract}
The aryl hydrocarbon receptor (AhR) recognizes a large number of xenobiotics, such as polyaromatic hydrocarbons (PAHs) and dioxins, and it activates several metabolic and detoxification pathways. Recent evidence suggests that this receptor also has important endogenous functions subsequent to activation by natural dietary compounds and/or endogenous metabolites. This receptor, thus, has physiological functions that extend beyond specific instances of detoxification. Understanding the roles played by this receptor might be enhanced by a systems biology approach. Indeed, the AhR "ligandome" is very complex and the different classes of ligands involved could induce widely diverse effects. The protein "interactome" of the AhR comprises several tens of proteins and it is altered by the binding of ligands to the receptor. Furthermore, large-scale studies have shown cell and tissue-specific patterns of regulated gene expression which may depend upon the type of ligand, although these aspects need further substantiation. Finally, the AhR biological effects are extensive and include detoxification, cellular proliferation and migration, immune regulation and neuronal effects. A holistic approach should provide a better understanding of the biology of this receptor in addition to providing new avenues for the identification of specific toxicity mechanisms.
\end{abstract}

Keywords: aryl hydrocarbon receptor; cell migration; development systems biology; toxicity.

\section{Introduction}

The aryl hydrocarbon receptor (AhR) is a ligand-activated transcription factor which is known to mediate most of the

*Corresponding author: Robert Barouki, INSERM UMR-S 747,

Université Paris Descartes, 45 rue des Saints Pères,

75006 Paris, France

Phone: +33-142862075, Fax: +33-142863868,

E-mail: robert.barouki@parisdescartes.fr

Received November 14, 2011; accepted December 19, 2011;

previously published online January 31, 2012 toxic and carcinogenic effects of a wide variety of environmental contaminants, such as polyaromatic hydrocarbons (PAHs) and dioxin (TCDD; 2,3,7,8-tetrachlorodibenzo$[p]$-dioxin). This receptor belongs to the basic-helix-loophelix (bHLH)/PAS (Period [Per]-Aryl hydrocarbon receptor nuclear translocator [Arnt]-single minded [Sim]) family of heterodimeric transcriptional regulators. bHLH/PAS proteins are involved in the control of diverse physiological processes, such as circadian rhythms, organ development, neurogenesis, metabolism and in the stress response to hypoxia (1-3). The extensive conservation of this receptor among species (4), the constitutive pattern of AhR expression during development and in adult tissues (5) and the phenotypic alterations found in mice lacking AhR expression (6-8) provide strong support for the involvement of the AhR in cellular physiological processes that extend beyond the metabolism of xenobiotics. A large number of recent studies support the involvement of the AhR in a variety of toxicity mechanisms as well as in endogenous biological functions. This diversity of AhR functions is further highlighted by the steady increase in the number and the type of ligands that bind to the receptor. Given the vastness of the profiles of the ligands bound, of the molecular mechanisms of action and of the outcomes of endogenous and exogenous AhR activation, a systems biology approach might lead to a more comprehensive understanding of this receptor. This review is an attempt to integrate several aspects of AhR biology based upon the recent literature.

\section{The life cycle of the AhR and its protein "interactome"}

Activation of the AhR leads to changes in the compartmentalization of the receptor within the cell. A large fraction of the unliganded AhR resides in the cytosolic compartment bound to a molecular chaperone complex (Hsp90/XAP2/ p23). The functions of these chaperones have been investigated extensively (9). It is believed that this complex maintains the AhR in a state of high affinity for ligands. Furthermore, several studies have suggested that the Src kinase is also bound to the AhR in its unliganded state. Upon ligand binding, the AhR complex dissociates, at least partially, thereby allowing the receptor to translocate into the nucleus (Figure 1). The dissociation of Src presumably leads to its activation $(10,11)$. In the nucleus, the dissociation of the AhR complex is completed and this receptor forms a heterodimer with ARNT (Ah receptor nuclear translocator). This heterodimer subsequently binds to a partially 


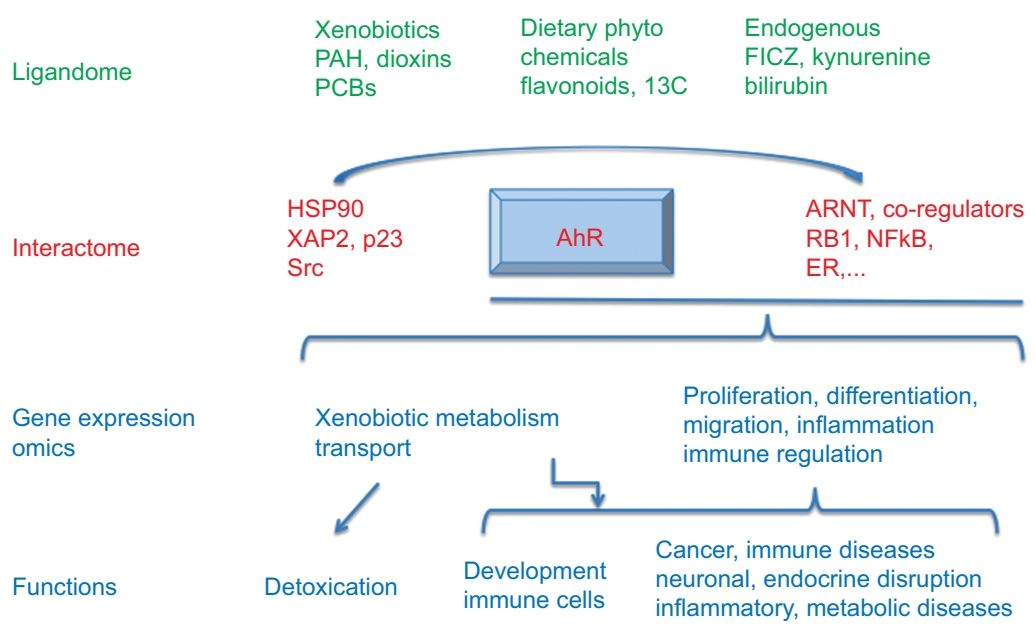

Figure 1 The aryl hydrocarbon receptor system.

Several classes of compounds (in green) are ligands of the AhR. Upon binding, the AhR complex with chaperone proteins (at the left, in red) is dissociated and the AhR migrates into the nucleus where it can interact with other proteins (at the right, in red). Evaluation of gene expression by omics techniques has identified numerous targets of the activated AhR leading to various functions in different organs.

characterized set of co-activators and/or co-repressors and the resulting complex interacts with consensus regulatory sequences (xenobiotic response elements, XREs) located upstream in the promoter of target genes (e.g., cytochromes P450, such as CYP1A1) (3). Several studies have revealed that the AhR is able to bind to a variety of transcription factors and regulatory proteins, such as Rb1, NF B and the Estrogen Receptor (ER). These physical interactions probably mediate the interference of certain AhR ligands with proliferation, inflammation and hormonal signaling. Once transcriptional regulation has occurred, the AhR is exported to the cytosol and degraded by the proteasome (12-14). Although the molecular events leading to the activation of the AhR in the presence of xenobiotics are well understood generally, the AhR signaling pathways, in the absence of exogenous ligands, remain largely unknown. Nevertheless, there is an increasing amount of experimental evidence that suggests that the AhR plays a role in cell proliferation and differentiation, in hepatic and immune system homeostasis and in tumor development.

\section{The AhR “ligandome"}

The AhR is a xenobiotic receptor that is involved in xenobiotic detection and detoxification. There are only a few xenobiotic receptors and, therefore, each one binds a large number of xenobiotics. The AhR has been identified as a receptor of environmental pollutants including PAHs, polyhalogenated hydrocarbons, such as dioxins, furans and polychlorinated biphenyls (PCBs), several prescription drugs and/or addictive compounds as well as natural phytochemicals, such as flavonoids, and indole derivatives, such as indolo[3,2-b]carbazole (Figure 1) (15-17). This wide ligand spectrum is abundantly present in the environment (cigarette smoke, combustion products, contaminated food, such as dioxins, PAH, PCBs, etc.), natural food products (polyphenols, metabolite derivatives, etc.) and, as a consequence, human populations are constantly exposed to AhR ligands. In addition to xenobiotics, the AhR can bind endogenous compounds, which may play roles in the endogenous physiological functions of the receptor. Several eicosanoids as well as bilirubin and biliverdin have been shown to bind and to activate the AhR. Among the bestcharacterized ligands are tryptophan photoproducts, such as FICZ (6-formylindolo[3,2-b]carbazole), which are generated by UV light. Recent studies have added new players to the field since kynurenine, a tryptophan metabolite, has also been shown to be a relevant endogenous AhR ligand with important implications for cancer development (18). It is remarkable that the spectrum of the AhR ligand includes polyaromatic planar xenobiotics as well as flavonoids or indole containing natural compounds including tryptophan metabolites. As will be discussed later, it is probable that these diverse ligands exert specific effects following their activation of AhR, which, although adding to the complexity of the system, also provides a framework for a multifunctional signaling system.

\section{The AhR phenome}

\section{Adaptive functions}

The AhR is an essential component of the adaptive xenobiotic stress system which recognizes putatively toxic xenobiotics and triggers their elimination. Hydrophobic and planar compounds, such as PAHs (e.g., benzopyrenes) or halogenated PAHs (dioxins) induce a subset of xenobiotic metabolizing enzymes, such as the cytochromes P450 (family 1) and phase 2 conjugating enzymes, as well as specific transporters. Ultimately, this metabolic pathway renders these hydrophobic compounds less toxic, more hydrophilic and, therefore, facilitates their elimination. Thus, the contribution to the 
xenobiotic stress is among the most important functions of the AhR. Although the AhR is clearly part of the xenobiotic detoxification adaptive pathway, it is nevertheless a mediator of the toxicity of several xenobiotics. This is due to the generation of highly reactive metabolites during the metabolism of certain xenobiotics and to the disruption or activation of other functions of the AhR that will be described in more detail in the following sections. Concerning the adaptive functions, this receptor may also contribute to autoregulatory loops that are not simply related to xenobiotic exposure. For example, FICZ is a photoproduct of trytophan and is generated following UV exposure. It is an excellent AhR ligand and is also metabolized by the AhR target CYP1A1. Another example is the lipoxin LXA4 which is an endogenous activator of the AhR and a substrate for CYP1A1. Finally, bilirubin is an agonist of the AhR and it is metabolized by the AhR enzyme target UGT1A1 (19).

\section{Endogenous functions derived from $\mathrm{AhR}^{-/-}$animal studies}

Critical arguments in favor of physiological roles for the AhR beyond that of detoxification derive from the analysis of the phenotype of $\mathrm{AhR}^{-/}$mice. These AhR-deficient mice exhibit several defects, which include a small liver size, probably due to a congenital vascular defect, alterations in immune function and cardiovascular development and decreased fertility $(8,20)$. These defects point to a function of the AhR in cellular differentiation and development. They may be due to a direct effect of the AhR on differentiation programs or to indirect effect via the modulation of developmental factors, such as retinoic acid or various growth factors and cytokines. The involvement of the AhR in differentiation and development is also supported by observations made in nonvertebrate organisms. In fact, in Drosophila, AhR orthologs (spineless) are involved in antenna and leg morphogenesis and, in Caenorhabditis elegans, the AhR ortholog (AhR1) appears to be required for the differentiation and migration of GABAergic neurons $(21,22)$. Interestingly, in these species, there is no evidence for participation of the AhR orthologs in xenobiotic detection. In conclusion, the control of cell fate, cell proliferation and migration is a likely endogenous function of the AhR and AhR orthologs.

\section{Cancer promotion}

Most of the studies devoted to the AhR have focused on its function as a mediator of its ligand toxicity. The most-studied ligand is the prototypical dioxin (TCDD) as it is widely accepted that most, if not all, effects of this pollutant are related to the activation of the AhR. Dioxins are usually present in the environment as a mix of chlorinated congeners. A total of 75 possible congeners have been identified and their toxicity is systematically expressed in relation to that of dioxin by means of a "toxic equivalent" quantification factor. The toxic effects of TCDD are numerous and include teratogenicity, immunosuppression, metabolic and endocrine disruption, skin toxicity, such as chloracne and keratosis, and cancer (23). Dioxin is considered by the International Agency for Research on Cancer as a human carcinogen. This designation is mostly based on the mechanism of action of the compound and on animal studies and, therefore, relies primarily on the ability of dioxin to activate the AhR. Dioxin exerts a carcinogenic effect on a wide variety of tissues and organs. In rodents, most studies have focused on liver carcinogenesis in which dioxin behaves as a cancer promoter. In humans, according to epidemiological studies, it appears that dioxin is a relatively weak non-specific carcinogen that can mildly increase the risk of developing a variety of tumors, such as non-Hodgkin lymphomas, sarcomas and breast cancer (24). The sensitivities of the various species to the carcinogenic effect of dioxin (high in some rodent species, mild in human) correlate well with the affinity of the AhR for dioxin in the species (4). In addition, the overexpression of a constitutively active AhR in mice leads to the development of stomach and liver cancers (25). All these observations establish a firm link between the carcinogenicity of dioxin and the activation of the AhR. Other carcinogens also exert their effects, at least partially, through the AhR. Benzo(a)pyrene, a PAH present in tobacco smoke and diesel particles also binds and activates the AhR. The mechanisms of its carcinogenicity include the production of highly reactive, genotoxic metabolites. $\mathrm{AhR}^{-1-}$ mice, however, are resistant to benzo(a)pyrene toxicity (26). Evidence suggesting that AhR may be involved in cancer, independent of its ligand has come from experiments in mice which overexpress a constitutively active AhR. These animals develop stomach and liver cancers, suggesting that AhR activity alone is sufficient for such a toxic effect (25). Conversely, immortalized mouse embryo fibroblasts which have their AhR genes deleted exhibit less tumorigenicity than wild-type fibroblasts in xenograft mouse models (27). Additional evidence comes from the examination of AhR gene polymorphisms in several human cancers. One particular polymorphism is found to adversely affect survival in patients suffering from soft tissue sarcoma (28).

\section{Immune function}

It is well known that several AhR ligands are immunotoxic. Furthermore, immune function disturbances have been observed in $\mathrm{AhR}^{--}$mice (8). Recent studies have strongly suggested that AhR participates in immune cell regulation. Indeed, it has been shown that the AhR is expressed in certain hematopoietic stem cells, certain thymocytes, dendritic cells and $\mathrm{T}$ cells. In particular, the AhR was shown to play a role in the differentiation of a subset of T cells, Th17, which are involved in autoimmune diseases $(29,30)$. In these cells, the AhR induces the production of the critical interleukin-22 cytokine which is involved in mucosal immune cell regulation, particularly in the intestine (31). Both endogenous and exogenous ligands of the AhR, such as FICZ and dioxin, influence its activity; however, these effects can be divergent, indicating a certain functional plasticity of this receptor depending upon the type of ligand. Recent studies have increased the repertoire of the AhR actions in immune system development. The AhR was found to be expressed in the innate lymphoid cells 
which lead to the formation of intestinal lymphoid follicles. These follicles are critical for defense against infection. The $\mathrm{AhR}$ is involved in the development of these follicles and it is activated by dietary phytochemicals (32). It is also critical for the development of intraepithelial lymphocytes which are the first defense barrier in skin and intestine (33). The relevance of AhR function in intestinal defense is revealed by the higher susceptibility of $\mathrm{AhR}^{-/-}$mice to intestinal infection by Citrobacter rodentium. Thus, in addition to the previously known roles of the AhR in immunotoxicity and in the regulation of thymocytes and dendritic cell functions, it is now believed that it could be involved in autoimmunity, inflammation and the defense against infections. The contribution of the AhR to the immune system now appears to be of primary importance.

\section{Nervous system}

As stated previously, the AhR orthologs in invertebrates (Spineless in Drosophila and AhR1 in Caenorhabditis) play critical functions in the differentiation of neurons and in the development of their cellular network $(22,34,35)$. Interestingly, these orthologs do not bind dioxins and other exogenous ligands. This suggests that the functions associated with the AhR in these models (specification of the GABAergic neuron cell fate, defects in neuronal differentiation associated with impaired cell migration, regulation of dendritic morphogenesis) are related to the endogenous functions of the receptor and/or to the binding of dietary ligands. Paradoxically, very few studies have been undertaken in vertebrates to assess the functions of the AhR during the development of the nervous system or in the animal behavior. In mammals, the AhR mRNA is expressed in several parts of the brain, including the cerebellum (36) and it seems to be important for the differentiation of specific neurons as it has been found that TCDD disrupts either the maturation of granule neuron precursors in the mouse developing cerebellum $(37,38)$ or their survival (39). However, the endogenous functions of the AhR or the influence of relevant endogenous ligands (kynureine, see below) on the AhR genomic or non-genomic pathways are still uncharacterized. One critical issue is whether or not exogenous ligands can have a disrupting effect on the endogenous function of the AhR. Such an effect could provide a link between environmental pollutants and impaired behaviors. This hypothesis needs to be considered and investigated in adults and certainly in developing organisms (e.g., in utero).

\section{A case study: interaction between the AhR system and the cell adhesion and migration system}

Transcriptomics experiments in mammalian model systems, including humans, have allowed the identification of new gene targets for dioxin and the AhR. We have identified several putative regulators of cellular migration (40). Furthermore, in the MCF-7 and HepG2 cell lines, we were able to show that activation of the AhR (achieved by the addition of ligands or using a cell line stably transfected with a constitutively activated AhR expressed only upon tetracycline withdrawal) leads to increased cell migration, Jun Kinase activation and E-cadherin down regulation (40). These features of cellular plasticity are reminiscent of epithelial mesenchymal transition (EMT)-related processes. EMT is defined as a phenotypic change (epithelial to mesenchymal) and is suspected to play critical roles during development, fibrosis and cancer metastasis $(40,41)$. The metastasis marker HEF1/NEDD9/CAS-L has been shown to be a target of the AhR and an essential node in AhR-regulated cell plasticity $(42,43)$. This protein is a multifunctional docking protein involved in integrin-based signaling that affects, notably, cell motility and oncogenic transformation $(44,45)$. HEF1 interacts with focal adhesion kinase (FAK) and the Src family of tyrosine kinases, two critical regulators of focal adhesion (46). As a result, HEF1/NEDD9/CAS-L regulates migratory processes, as demonstrated in a melanoma cell line, and its overexpression has been suggested to be a metastasis marker in several human cancers (47-49). Other studies support the role of the endogenously activated AhR in cell migration. It has been shown, using immortalized cell lines from wild-type $\left(\mathrm{AhR}^{+/+}\right)$and mutant $\left(\mathrm{AhR}^{--}\right)$mouse mammary fibroblasts, that $\mathrm{AhR}$-deficient cells had a lesser tendency to develop subcutaneous tumors in immunodeficient mice. In cell culture experiments, those cells also displayed reduced migration properties and lamellipodia formation. This could be related to the down regulation of the ERK-FAK-PKB/AKT-Rac-1 pathway in the $\mathrm{AhR}^{-/}$cells $(27,50)$. In another recent study, Vav3, a guanosine diphosphate/ guanosine triphosphate exchange factor for Rho/Rac GTPases (identified as a transcriptional target of AhR) was shown to be involved in the regulation of cell morphology and migration (50). Interestingly, the status of AhR expression does not lead to similar phenotypes in all cell models. In fact, deficiency of the AhR was shown to increase keratinocyte migration and to accelerate skin re-epithelialization, probably due to increased secretion of transforming growth factor $\beta$ by AhR null dermal fibroblasts (51). The regulation of cell migration by the AhR in the absence of xenobiotic exposure has also been observed in nematodes lacking the AhR ortholog. These worms display aberrant neuron migration, axon branching and axonal migration defects (34). Several important conclusions can be drawn from these studies. First, the regulation of cell migration by the AhR might be an ancestral function as clearly suggested by the invertebrate studies. Second, this effect is not necessarily related to stimulation of the AhR by xenobiotics but could also be activated by endogenous triggers and is highly dependent on the cellular context. Third, xenobiotics could either support and magnify the endogenous function of the AhR or antagonize it.

Recent studies on glioma have shown that the regulation of cancer cell migration and of immune cell functions by AhR could be synergistic and lead to uncontrolled tumor development (18). In these studies, the tryptophan metabolite, kynurenine was identified as an endogenous activating ligand of the AhR.

\section{Conclusions}

Although the AhR was initially believed to be a dedicated xenobiotic receptor that had as its function the induction of 
a battery of genes involved in adaptive transport and metabolism, it is now clear that it has a much wider physiological relevance. A systems biology approach is well suited for such a complex biological node and it has been applied only very partially. A full scale "interactome" of the AhR in the absence or in the presence of diverse chemicals would help dissect its functional roles. Similarly, three-dimensional structural information for the receptor is also critical as it would help to understand the different types of structural modifications elicited by endogenous and exogenous compounds. Indeed, this receptor binds hundreds, maybe thousands, of chemicals with diverse properties and there are reasons to believe that they do not activate similar pathways. In addition to affinity and toxic equivalency, it is critical to add qualitative functional outcomes for each ligand (which pathway is activated, which genes and by which ligand, etc.). This should clearly be linked to available and additional omics studies that will help define the pathways. Finally, as discussed in this review, there are diverse physiological and pathological phenotypic outcomes that are controlled by the AhR either alone or with endogenous or exogenous chemicals. An ultimate goal would be to link the classes of ligands with the type of effects they elicit.

Clearly, such a systematic approach could provide a better understanding of the physiological role of the AhR system and could also open new perspectives for elucidating toxicity mechanisms.

\section{Conflict of interest statement}

Authors' conflict of interest disclosure: The authors stated that there are no conflicts of interest regarding the publication of this article.

Research funding: None declared.

Employment or leadership: None declared.

Honorarium: None declared.

\section{References}

1. Crews ST. Control of cell lineage-specific development and transcription by bHLH-PAS proteins. Genes Dev 1998;12:607-20.

2. Gonzalez FJ, Fernandez-Salguero P. The aryl hydrocarbon receptor: studies using the AHR-null mice. Drug Metab Dispos 1998;26:1194-8.

3. Whitlock JP Jr. Induction of cytochrome P4501A1. Annu Rev Pharmacol Toxicol 1999;39:103-25.

4. Hahn ME. Aryl hydrocarbon receptors: diversity and evolution. Chem Biol Interact 2002;141:131-60.

5. Abbott BD, Birnbaum LS, Perdew GH. Developmental expression of two members of a new class of transcription factors: I. Expression of aryl hydrocarbon receptor in the C57BL/6N mouse embryo. Dev Dyn 1995;204:133-43.

6. Schmidt JV, Su GH-T, Reddy JK, Simon MC, Bradfield CA. Characterization of a murine Ahr null allele: involvement of the Ah receptor in hepatic growth and development. Proc Natl Acad Sci USA 1996;93:6731-6.

7. Mimura J, Yamashita K, Nakamura K, Morita M, Takagi TN, Nakao K, et al. Loss of teratogenic response to 2,3,7,8- tetrachlorodibenzo-p-dioxin (TCDD) in mice lacking the Ah (dioxin) receptor. Genes Cells 1997;2:645-54.

8. Fernandez-Salguero P, Pineau T, Hilbert DM, McPhail T, Lee SS, Kimura S, et al. Immune system impairment and hepatic fibrosis in mice lacking the dioxin-binding Ah receptor. Science 1995;268:722-6.

9. Soshilov A, Denison MS. Ligand displaces heat shock protein 90 from overlapping binding sites within the aryl hydrocarbon receptor ligand-binding domain. J Biol Chem 2011;286:35275-82.

10. Blankenship A, Matsumura F. 2,3,7,8-Tetrachlorodibenzop-dioxin (TCDD) causes an Ah receptor-dependent and ARNTindependent increase in membrane levels and activity of p60( $\mathrm{Src})$. Environ Toxicol Pharmacol 1997;3:211-20.

11. Dong B, Cheng W, Li W, Zheng J, Wu D, Matsumura F, et al. FRET analysis of protein tyrosine kinase c-Src activation mediated via aryl hydrocarbon receptor. Biochim Biophys Acta 2011;1810:427-31.

12. Davarinos NA, Pollenz RS. Aryl hydrocarbon receptor imported into the nucleus following ligand binding is rapidly degraded via the cytoplasmic proteasome following nuclear export. J Biol Chem 1999;274:28708-15.

13. Ma Q, Baldwin KT. 2,3,7,8-Tetrachlorodibenzo-p-dioxininduced degradation of aryl hydrocarbon receptor (AhR) by the ubiquitin-proteasome pathway. Role of the transcription activation and DNA binding of AhR. J Biol Chem 2000;275:8432-8.

14. Santiago-Josefat B, Fernandez-Salguero PM. Proteasome inhibition induces nuclear translocation of the dioxin receptor through an Sp1 and protein kinase C-dependent pathway. J Mol Biol 2003;333:249-60.

15. Denison MS, Nagy SR. Activation of the aryl hydrocarbon receptor by structurally diverse exogenous and endogenous chemicals. Annu Rev Pharmacol Toxicol 2003;43:309-34.

16. Heath-Pagliuso S, Rogers WJ, Tullis K, Seidel SD, Cenijn PH, Brouwer A, et al. Activation of the Ah receptor by tryptophan and tryptophan metabolites. Biochemistry 1998;37:11508-15.

17. Miller CA 3rd. Expression of the human aryl hydrocarbon receptor complex in yeast. Activation of transcription by indole compounds. J Biol Chem 1997;272:32824-9.

18. Opitz CA, Litzenburger UM, Sahm F, Ott M, Tritschler I, Trump $\mathrm{S}$, et al. An endogenous tumour-promoting ligand of the human aryl hydrocarbon receptor. Nature 2011;478:197-203.

19. Bock KW, Köhle C. Contributions of the Ah receptor to bilirubin homeostasis and its antioxidative and atheroprotective functions. Biol Chem 2010;391:645-53.

20. Barouki R, Coumoul X, Fernandez-Salguero PM. The aryl hydrocarbon receptor, more than a xenobiotic-interacting protein. FEBS Lett 2007;581:3608-15.

21. Emmons RB, Duncan D, Estes PA, Kiefel P, Mosher JT, Sonnenfeld M, et al. The spineless-aristapedia and tango bHLHPAS proteins interact to control antennal and tarsal development in Drosophila. Development 1999;126:3937-45.

22. Huang X, Powell-Coffman JA, Jin Y. The AHR-1 aryl hydrocarbon receptor and its co-factor the AHA-1 aryl hydrocarbon receptor nuclear translocator specify GABAergic neuron cell fate in C. elegans. Development 2004;131:819-28.

23. Bock KW, Köhle C. Ah receptor: dioxin-mediated toxic responses as hints to deregulated physiologic functions. Biochem Pharmacol 2006;72:393-404.

24. Steenland K, Bertazzi P, Baccarelli A, Kogevinas M. Dioxin revisited: developments since the 1997 IARC classification of dioxin as a human carcinogen. Environ Health Perspect 2004;112:1265-8. 
25. Andersson P, McGuire J, Rubio C, Gradin K, Whitelaw ML, Pettersson S, et al. A constitutively active dioxin/aryl hydrocarbon receptor induces stomach tumors. Proc Natl Acad Sci USA 2002;99:9990-5.

26. Nakatsuru Y, Wakabayashi K, Fujii-Kuriyama Y, Ishikawa T, Kusama K, Ide F. Dibenzo[A,L]pyrene-induced genotoxic and carcinogenic responses are dramatically suppressed in aryl hydrocarbon receptor-deficient mice. Int J Cancer 2004;112:179-83.

27. Mulero-Navarro S, Pozo-Guisado E, Pérez-Mancera PA, Alvarez-Barrientos A, Catalina-Fernández I, Hernández-Nieto E, et al. Immortalized mouse mammary fibroblasts lacking dioxin receptor have impaired tumorigenicity in a subcutaneous mouse xenograft model. J Biol Chem 2005;280:28731-41.

28. Berwick M, Matullo G, Song YS, Guarrera S, Dominguez G, Orlow I, et al. Association between aryl hydrocarbon receptor genotype and survival in soft tissue sarcoma. J Clin Oncol 2004;22:3997-4001.

29. Kimura A, Naka T, Nohara K, Fujii-Kuriyama Y, Kishimoto T. Aryl hydrocarbon receptor regulates Stat 1 activation and participates in the development of Th17 cells. Proc Natl Acad Sci USA 2008;105:9721-6.

30. Veldhoen M, Hirota K, Westendorf AM, Buer J, Dumoutier L, Renauld JC, et al. The aryl hydrocarbon receptor links TH17cell-mediated autoimmunity to environmental toxins. Nature 2008;453:106-9.

31. Esser C, Rannug A, Stockinger B. The aryl hydrocarbon receptor in immunity. Trends Immunol 2009;30:447-54.

32. Kiss EA, Vonarbourg C, Kopfmann S, Hobeika E, Finke D, Esser C, et al. Natural aryl hydrocarbon receptor ligands control organogenesis of intestinal lymphoid follicles. Science 2011;334:1561-5.

33. Li Y, Innocentin S, Withers DR, Roberts NA, Gallagher AR, Grigorieva EF, et al. Exogenous stimuli maintain intraepithelial lymphocytes via aryl hydrocarbon receptor activation. Cell 2011;147:629-40.

34. Qin H, Powell-Coffman JA. The Caenorhabditis elegans aryl hydrocarbon receptor, AHR-1, regulates neuronal development. Dev Biol 2004;270:64-75.

35. Crews ST, Brenman JE. Spineless provides a little backbone for dendritic morphogenesis. Genes Dev 2006;20:2773-8.

36. Petersen SL, Curran MA, Marconi SA, Carpenter CD, Lubbers LS, McAbee MD. Distribution of mRNAs encoding the arylhydrocarbon receptor, arylhydrocarbon receptor nuclear translocator, and arylhydrocarbon receptor nuclear translocator- 2 in the rat brain and brainstem. J Comp Neurol 2000;427:428-39.

37. Collins LL, Williamson MA, Thompson BD, Dever DP, Gasiewicz TA, Opanashuk LA. 2,3,7,8-Tetracholorodibenzo-p-dioxin exposure disrupts granule neuron precursor maturation in the developing mouse cerebellum. Toxicol Sci 2008;103:125-36.

38. Kim SY, Yang JH. Neurotoxic effects of 2,3,7,8-tetrachlorodibenzo-p-dioxin in cerebellar granule cells. Exp Mol Med 2005;37:58-64.
39. Sánchez-Martín FJ, Fernández-Salguero PM, Merino JM. Aryl hydrocarbon receptor-dependent induction of apoptosis by 2,3,7,8-tetrachlorodibenzo-p-dioxin in cerebellar granule cells from mouse. J Neurochem 2011;118:153-62.

40. Diry M, Tomkiewicz C, Koehle C, Coumoul X, Bock KW, Barouki R, et al. Activation of the dioxin/aryl hydrocarbon receptor (AhR) modulates cell plasticity through a JNKdependent mechanism. Oncogene 2006;25:5570-4.

41. Hugo H, Ackland ML, Blick T, Lawrence MG, Clements JA, Williams ED, et al. Epithelial-mesenchymal and mesenchymalepithelial transitions in carcinoma progression. J Cell Physiol 2007;213:374-83.

42. Frueh FW, Hayashibara KC, Brown PO, Whitlock JP Jr. Use of cDNA microarrays to analyze dioxin-induced changes in human liver gene expression. Toxicol Lett 2001;122:189-203.

43. Bui LC, Tomkiewicz C, Chevallier A, Pierre S, Bats AS, Mota $\mathrm{S}$, et al. Nedd9/Hef1/Cas-L mediates the effects of environmental pollutants on cell migration and plasticity. Oncogene 2009;28:3642-51.

44. Astier A, Manie SN, Law SF, Canty T, Haghayghi N, Druker BJ, et al. Association of the Cas-like molecule HEF1 with CrkL following integrin and antigen receptor signaling in human B-cells: potential relevance to neoplastic lymphohematopoietic cells. Leuk Lymphoma 1997;28:65-72.

45. Izumchenko E, Singh MK, Plotnikova OV, Tikhmyanova N, Little JL, Serebriiskii IG, et al. NEDD9 promotes oncogenic signaling in mammary tumor development. Cancer Res 2009;69:7198-206.

46. van Seventer GA, Salmen HJ, Law SF, O’Neill GM, Mullen MM, Franz AM, et al. Focal adhesion kinase regulates beta1 integrindependent $\mathrm{T}$ cell migration through an HEF1 effector pathway. Eur J Immunol 2001;31:1417-27.

47. Kim M, Gans JD, Nogueira C, Wang A, Paik JH, Feng B, et al. Comparative oncogenomics identifies NEDD9 as a melanoma metastasis gene. Cell 2006;125:1269-81.

48. Natarajan M, Stewart JE, Golemis EA, Pugacheva EN, Alexandropoulos K, Cox BD, et al. HEF1 is a necessary and specific downstream effector of FAK that promotes the migration of glioblastoma cells. Oncogene 2006;25:1721-32.

49. Ji H, Ramsey MR, Hayes DN, Fan C, McNamara K, Kozlowski $\mathrm{P}$, et al. LKB1 modulates lung cancer differentiation and metastasis. Nature 2007;448:807-10.

50. Carvajal-Gonzalez JM, Mulero-Navarro S, Roman AC, Sauzeau $\mathrm{V}$, Merino JM, Bustelo XR, et al. The dioxin receptor regulates the constitutive expression of the vav3 proto-oncogene and modulates cell shape and adhesion. Mol Biol Cell 2009;20: 1715-27.

51. Carvajal-Gonzalez JM, Roman AC, Cerezo-Guisado MI, Rico-Leo EM, Martin-Partido G, Fernandez-Salguero PM. Loss of dioxin-receptor expression accelerates wound healing in vivo by a mechanism involving TGFbeta. J Cell Sci 2009;122:1823-33. 